\title{
Si-RNA mediated knockdown of CELF1 gene suppressed the proliferation of human lung cancer cells
}

Li-Na Wu ${ }^{1 \dagger}$, Yi-Jun Xue ${ }^{2 \dagger}$, Li-Jian Zhang ${ }^{3}$, Xue-Mei Ma ${ }^{2}$ and Jin-Feng Chen ${ }^{3 *}$

\begin{abstract}
Background: Lung cancer is the leading cause of cancer-related death in the world, with metastasis as the main reason for the mortality. CELF1 is an RNA-binding protein controlling the post-transcriptional regulation of genes related to cell survival. As yet, there is little knowledge of CELF1 expression and biological function in lung cancer. This study investigated the expression levels of CELF1 in lung cancer tissues and the biological function of CELF1 in lung cancer cells.

Methods: CELF1 mRNA expression was determined in lung cancer and normal tissues, and the relationship between the expression level of CELF1 and clinicopathological parameters was evaluated. The biological function of CELF1 in A549 and H1299 lung cancer cell lines growth was examined.

Results: The expression of CELF1 was higher in human lung cancer tissues compared with the normal lung tissue. Lentiviral-mediated transfection of CELF1 siRNA effectively silenced the expression of CELF1 in both A549 and H1299 cells. Moreover, CELF1 knockdown markedly reduced the survival rate of lung cancer cells. Colony formation assays revealed a reduction in the number and size of lung cancer cell colonies from CELF1 knockdown.

Conclusion: These results indicated that CELF1 may have significant roles in the progression of lung cancer, and suggested that siRNA mediated silencing of CELF1 could be an effective tool in lung cancer treatment.
\end{abstract}

Keywords: Lung cancer, CELF1 gene, Proliferation

\section{Introduction}

Lung cancer is one of the leading causes of cancerrelated deaths worldwide [1]. Studies have shown that the genes and target proteins involved in lung cancer function in cell proliferation [2], apoptosis [3], and angiogenesis [4] pathways. Identifying a mechanism that inhibits the growth of lung cancer metastasis would be useful in developing potential treatments for lung cancer. Veale D et al. first reported the epidermal growth factor receptor (EGFR) was associated with spread of human non-small cell lung cancer and might be a potential therapeutic target in many carcinomas [5]. Now, the EGFR superfamily is well known to promote cancer cell

\footnotetext{
*Correspondence: chengjinfeng123@163.com

${ }^{\dagger}$ Equal contributors

${ }^{3}$ Key laboratory of Carcinogenesis and Translational Research (Ministry of Education), Department of Thoracic Surgery II, Peking University Cancer Hospital \& Institute, Beijing 100142, China

Full list of author information is available at the end of the article
}

growth, and has become a therapeutic target for lung cancer and changed the lung cancer treatment model. By exploring new cancer-related genes and clearly identifying the roles of these genes in tumor development and progression, not only can we obtain a deeper understanding of the nature of tumors, but we can also discover new tumor therapeutic targets.

The CELF (CUGBP and Etr-like factors) family proteins are major sequence-specific RNA binding proteins that control alternative splicing and mRNA translation and stability [6,7]. Some reports have demonstrated that CELF1 protein regulates pre-mRNA alternative splicing and is involved in mRNA editing and translation [8-10]. Whether the expression of the CELF1 gene is related to the proliferation of human lung cancer has not been investigated.

Here we investigated the relationship between CELF1 expression and lung cancer clinicopathological factors at

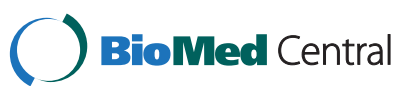


the RNA level and clarified the physiological impact of CELF1 on lung cancer cell growth at the cellular level.

\section{Results}

\section{Expression of CELF1 in lung cancer tissues}

To evaluate the levels of CELF1 expression in lung cancer tissues and normal tissues, real time PCR was performed in 10 lung cancer tissues and 10 normal tissues. Results showed that the relative expression levels of CELF1 were higher in lung cancer tissues compared with the normal tissues (Figure 1A and Table 1). Moreover, the expression levels of CELF1 in lung cancer tumors varied depending on tumor grade. CELF1 expression levels were higher in low-grade cancers compared with high-grade cancers (Figure 1B). A higher expression level of CELF1 was observed in patients with the increase of $\mathrm{T}$ stage, indicating that when tumors begin to grow larger, gradually some other mechanism(s) may play a more important role to promote cancer cell growth, so the CELF1 expression level had some decrease. Furthermore, comparison of the survival rate of patients with $\mathrm{N} 1$ and N2 lymph node metastasis and without lymph node metastasis showed that the survival rates were significantly higher in the absence of lymph node metastasis (Figure 1C). In comparing the survival rate with CELF1 expression levels, no significant difference in survival rate was observed between patients with higher CELF1 expression and lower expression (Figure 1D). Together these data indicate that CELF1 expression is not related to postoperative survival in lung cancer patients.

\section{Effect of CELF1 siRNA on the expression levels of CELF1 in lung cancer cells}

Next, CELF1 mRNA and protein levels in A549 and H1299 lung cancer cells were evaluated by real time PCR and western blot, respectively. As shown in Figure 2, both gene and protein expression of CELF1 were detected in A549 and H1299 cells. The CELF1expressing lung cancer cells were then infected with lentivirus containing CELF1 shRNA or non-silencing control shRNA, and successful infection was confirmed by green fluorescence of
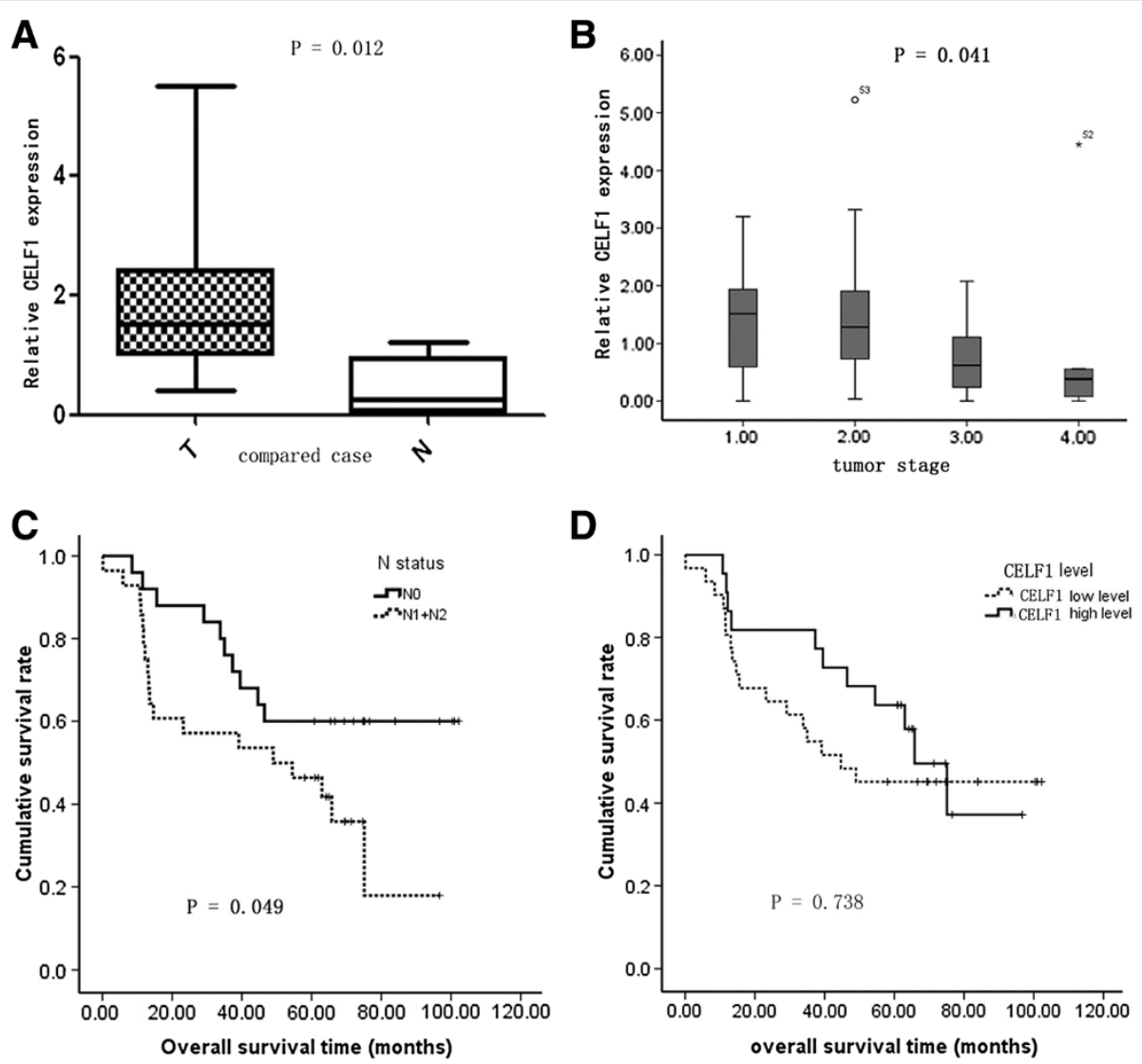

Figure 1 Expression levels of CELF1 in lung cancer tissues. (A) Expression levels of CELF1 in 10 lung cancer tissues compared with normal lung tissues analyzed by real time PCR. (B) Expression of CELF1 in lung cancers at different stages analyzed by real time PCR. (C) Comparison of the survival rate of patients with N1 and N2 lymph node metastasis and without lymph node metastasis. (D) Comparison of the survival rate with levels of CELF1 expression. The values represents the mean from three independent experiments; bars represent SD. ${ }^{*} P<0.05,{ }^{*} P<0.01$ compared with controls. 
Table 1 Expression level of CELF1 in lung carcinoma and relationship to clinicopathological parameters

\begin{tabular}{|c|c|c|c|c|}
\hline \multirow[t]{2}{*}{ Variable } & \multirow[t]{2}{*}{ Case no. } & \multicolumn{2}{|c|}{ CELF1 expression (RQ: $2^{-\Delta \Delta C T}$ ) } & \multirow[t]{2}{*}{$P$ value } \\
\hline & & Median & Mean \pm SEM & \\
\hline \multicolumn{5}{|l|}{ Gender } \\
\hline Male & 41 & 1.1090 & $1.2458 \pm 0.9115$ & \multirow[t]{2}{*}{0.183} \\
\hline Female & 12 & 0.7252 & $0.8938 \pm 103.53$ & \\
\hline \multicolumn{5}{|l|}{ Age } \\
\hline$\leq 60.5$ & 32 & 0.9000 & $1.0103 \pm 0.8746$ & \multirow[t]{2}{*}{0.118} \\
\hline$>60.5$ & 21 & 0.1164 & $1.4035 \pm 1.4948$ & \\
\hline \multicolumn{5}{|l|}{ Venous invasion } \\
\hline Negative & 40 & 1.0274 & $1.2302 \pm 1.2217$ & \multirow[t]{2}{*}{0.251} \\
\hline Positive & 13 & 0.5492 & $0.9687 \pm 0.9781$ & \\
\hline \multicolumn{5}{|l|}{ T stage } \\
\hline $\mathrm{T} 1$ & 7 & 1.5105 & $1.396 \pm 1.1033$ & \multirow[t]{4}{*}{0.041} \\
\hline $\mathrm{T} 2$ & 21 & 1.2776 & $1.5178 \pm 1.2898$ & \\
\hline $\mathrm{T} 3$ & 17 & 0.6242 & $0.8040 \pm 0.7079$ & \\
\hline T4 & 8 & 0.3816 & $0.8109 \pm 1.4910$ & \\
\hline \multicolumn{5}{|l|}{ N stage } \\
\hline NO & 25 & 0.6242 & $0.9983 \pm 1.1184$ & \multirow[t]{3}{*}{0.251} \\
\hline N1 & 11 & 1.3165 & $1.4731 \pm 1.4334$ & \\
\hline N2 & 17 & 1.1164 & $1.2142 \pm 1.0611$ & \\
\hline \multicolumn{5}{|l|}{ Lymph node status } \\
\hline No & 25 & 0.6242 & $0.9983 \pm 1.1184$ & \multirow[t]{2}{*}{0.164} \\
\hline $\mathrm{N} 1+\mathrm{N} 2$ & 28 & 1.2321 & $1.3159 \pm 1.2020$ & \\
\hline \multicolumn{5}{|l|}{ TNM stage } \\
\hline la & 4 & 1.2109 & $1.4055 \pm 1.3481$ & \multirow[t]{6}{*}{0.089} \\
\hline $\mathrm{lb}$ & 6 & 1.2500 & $1.4397 \pm 0.9834$ & \\
\hline Ila & 5 & 1.3322 & $2.1861 \pm 1.7131$ & \\
\hline$\| \mathrm{b}$ & 13 & 0.6242 & $0.7331 \pm 0.5595$ & \\
\hline IIla & 23 & 0.6624 & $1.1535 \pm 1.2526$ & \\
\hline$\| l \mid b$ & 2 & 0.2747 & $0.2747 \pm 0.3882$ & \\
\hline \multicolumn{5}{|l|}{ Differentiation } \\
\hline Well & 6 & 1.0545 & $0.8122 \pm 0.5568$ & \multirow[t]{3}{*}{0.256} \\
\hline Moderate & 28 & 0.9000 & $1.1866 \pm 1.1315$ & \\
\hline Poor & 19 & 1.0548 & $1.2476 \pm 1.3613$ & \\
\hline \multicolumn{5}{|l|}{ Compared case } \\
\hline Tumor tissue & 10 & 1.5263 & $1.9005 \pm 1.4382$ & \multirow[t]{2}{*}{0.012} \\
\hline Normal tissue & 10 & 0.2509 & $0.4579 \pm 0.4761$ & \\
\hline
\end{tabular}

infected cells (Figure 3A and B). Fluorescence analysis showed that the lentiviral infection rate was higher in H1299 cells than in A549 cells. Infection of cells with lentivirus containing CELF1 shRNA significantly reduced CELF1 gene and protein expression levels in both A549 and H1299 cells (Figure 3C-F). In contrast, the nonsilencing siRNA infection had no effect on CELF1 levels, confirming that CELF1 expression levels were reduced specifically from CELF1 siRNA.

\section{Effect of CELF1 knockdown on the survival of lung cancer cells}

The effect of CELF1 knockdown on lung cancer cell survival was analyzed using a MTT assay performed over a five-day time course. In both cell lines, significant differences in cell survival were not observed until three days after infection. From the $4^{\text {th }}$ day of infection onwards, significant differences in cell survival were observed in both cell lines. The survival rate of CELF1 knockdown cells was markedly $(P<0.0001)$ reduced at the $5^{\text {th }}$ day of infection compared with the non-infected and control siRNA infected A549 and H1299 cells (Figure 4). The reduction in cell survival due to CELF1 knockdown was higher in A549 cells than in H1299 cells.

\section{Effect of CELF1 knockdown on the colony forming ability of lung cancer cells}

Lung cancer cells tend to form large cell colonies while in culture; therefore, we next evaluated the effect of CELF1 silencing on the colony forming ability of lung cancer cells. As shown in Figure 5A and B, the size of colonies in CELF1-silenced A549 and H1299 cells was markedly reduced compared with the control groups. Similarly, the number of colonies was also significantly $(P<0.001)$ reduced with the CELF1 gene knockdown. Together these results indicate that CELF1 plays an important role in the growth progression of lung cancer cells.

\section{Discussion}

With increasing mortality rates, lung carcinoma has already become the leading cause of cancer mortality in the world [11]. Many genes are subjected to posttranscriptional regulation via control of the rate of mRNA turnover for transcripts bearing destabilizing ciselements [12]. Among the very few regulatory factors identified thus far, CELF1 regulates post-transcriptional gene expression by facilitating alternative splicing, translation [13], and mRNA degradation, and it functions by binding directly to RNA [14]. Rattenbacher et al. identified the CELF1 gene and its target proteins as a critical posttranscriptional regulatory network that may play a role in the development of cancer [8]. In addition to reports of involvement in breast cancer and leukemia development, the CELF1 gene may also play a significant role in tumorigenesis and the deterioration of certain tumors [15], which is also confirmed by the results in our present study.

Timchenko et al. first identified CELF1 function in the regulation of translation of C/EBP beta isoforms [6]. Subsequent research demonstrated that members of this 

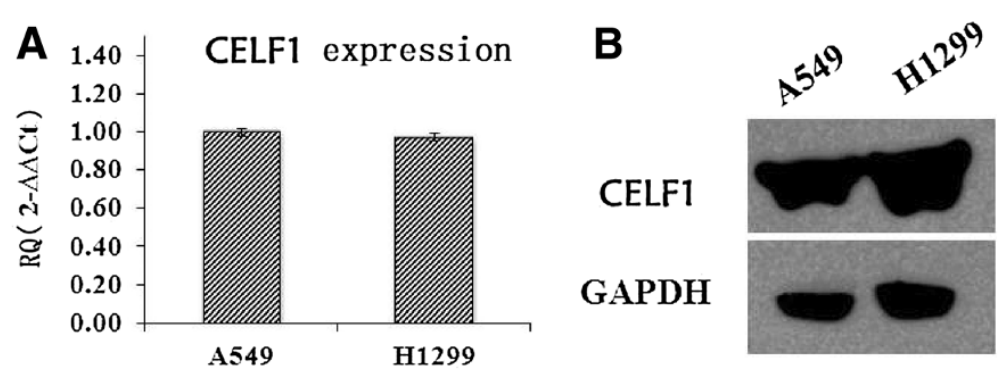

Figure 2 Expression levels of CELF1 in lung cancer cells. (A). Expression levels of CELF1 in A549 and H1299 cells analyzed by real time PCR. (B). Protein expression levels of CELF1 in A549 and H1299 cells analyzed by western blotting. The values represents the mean from three independent experiments; bars represent SD. ${ }^{*} P<0.05,{ }^{*} P<0.01$ compared with controls.

protein family regulate pre-mRNA alternative splicing and may also be involved in mRNA editing and translation [16]. The CELF1 gene may play a role in myotonic dystrophy type 1 (DM1) via interactions with the dystrophia myotonica-protein kinase (DMPK) gene [10]. A previous report identified a correlation between the expression of CELF1 and human lung cancer [17]. However, the cellular mechanism underlying how the CELF1 gene causes this phenomenon has not been clarified. Together these findings implicate possible involvement of the CELF1 gene in cell growth. So far there is no literature reporting the biological function of CELF1 gene in lung cancer cell. We speculate that CELF1 may also play an important role in lung cancer proliferation.

Our research primarily focused on the effect of CELF1 knockdown on the viability of lung cancer cells. As shown in the results, the expression of CELF1 was higher in human lung cancer tissues compared with normal tissues. Moreover, A549 and H1299 lung cancer cells also exhibited CELF1 expression in mRNA and protein level. Lentiviral-mediated delivery of CELF1 silencing siRNA significantly inhibited these upregulated levels of CELF1 expression, demonstrating that the CELF1 knockdown method was successful. Further in vivo studies should be performed to confirm the use of this siRNA method as a potential therapeutic tool.

Interestingly, upon knockdown of CELF1, the survival rates and colony forming ability of lung cancer cells were markedly reduced, indicating pivotal roles of CELF1 in the survival of lung cancer cells. Reports in the literature have suggested that upregulation of CELF1 increased the turnover of oncogenes related to the proliferation of lung cancer cells $[7,9,18]$. Hence, in the absence of CELF1, the turnover of possible oncogenes could presumably

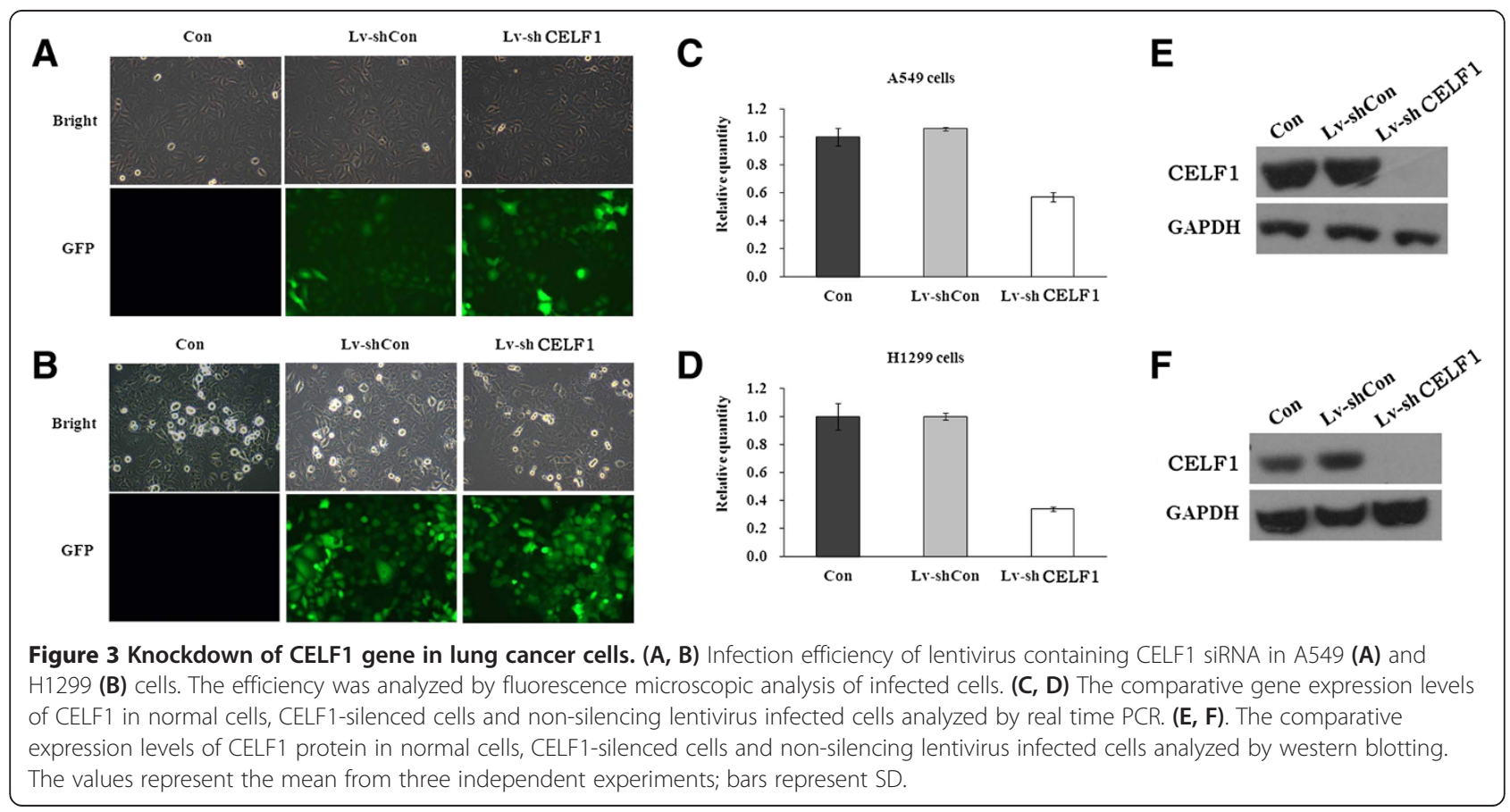



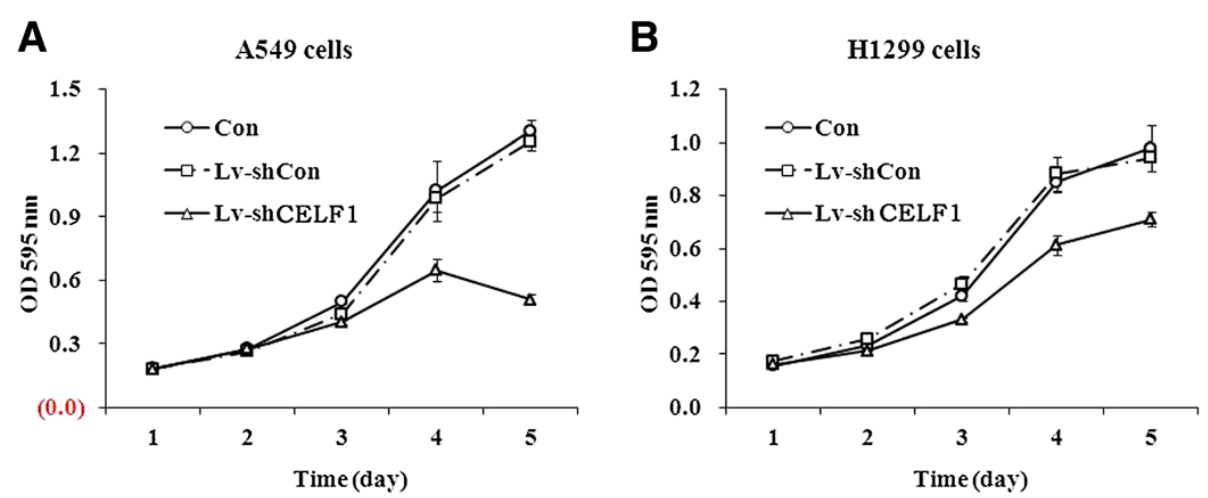

Figure 4 Effect of CELF1 gene knockdown on the proliferation of lung cancer cells. Proliferation of A549 (A) and A1299 (B) cells were treated as indicated and measured by MTT assay. The values represents the mean from three independent experiments; bars represent SD. ${ }^{* * *} P<0.001$ compared with controls.

decrease, consistent with the cancer cells showing decreased capacity of proliferation and colony formation. Our study showed that CELF1 is overexpressed in lung cancer tissue on RNA level compared with the normal lung tissue and tumor grades had relationship with CELF1 expression level, which is line with the hypothesis mentioned above.

From these results, we can conclude that CELF1 can affect the growth of lung cancer cells and plays an important role in the tumor development process. Further research on the molecular mechanisms of the CELF1 gene is required, particularly in identifying CELF1interacting proteins, elucidating the molecular mechanisms underlying its biological effects, and determining whether it plays a guiding role in the treatment of lung cancer.

\section{Conclusion}

In summary, CELF1 may have significant roles in the progression of lung carcinoma. The CELF1 siRNA method has emerged as a potentially powerful tool for cancer therapeutics in silencing genes responsible for cancer progression and tumorigenesis.

\section{Materials and methods}

\section{Human specimens and reagents}

Fifty-three pulmonary cancer samples of fresh frozen tissue were acquired from the Department of Thoracic
A

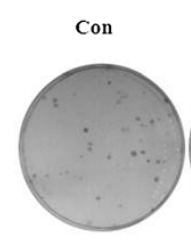

Lv-shCon

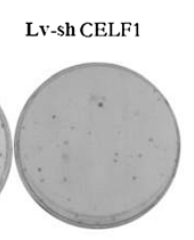

B

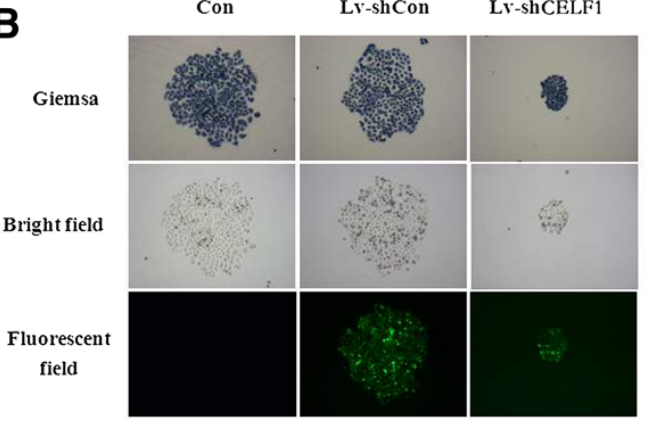

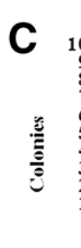

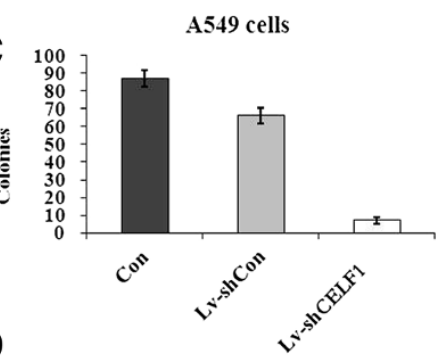

D

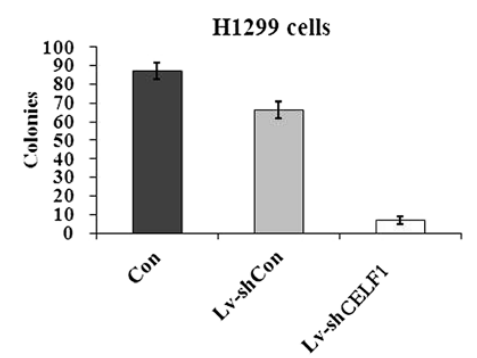

Figure 5 Effect of CELF1 gene knockdown on the colony forming ability of lung cancer cells. (A, B) The cancer cell colonies under light, bright field and fluorescence microscopy. The colonies were stained with Giemsa staining. The images show comparison of the size of colonies in normal, CELF1-silenced and non-silenced lung cancer cells. (C, D) The number of colonies in normal, CELF1-silenced and non-silenced lung cancer cells. The values represents the mean from three independent experiments; bars represent SD. ${ }^{*} P<0.01,{ }^{* *} P<0.001$ compared with controls. 
Surgery, Beijing cancer hospital, under approval from the Ethical Committee. Written consent statements were obtained from all patients before operation. None of the patients received any neoadjuvant therapy prior to surgery. The tissues were collected immediately after surgical resection at the Beijing Cancer Hospital and stored at the Tissue Bank of Peking University Oncology School. Clinicopathological characteristics of the tumors were defined according to the TNM staging system criteria of UICC. Clinicopathological factors are shown in Table 1.

AgeI, EcoRI, and SYBRGreen Master Mix Kits were purchased from TaKaRa (Dalian, China). pHelper1.0, pHelper 2.0, and pGCSIL-GFP plasmids were purchased from Genechem Co. Ltd (Shanghai, China). The RNeasy Midi Kit was from Qiagen (Valencia, CA, USA). Dulbecco's modified Eagle's medium (DMEM), Roswell Park Memorial Institute 1640 (RPMI 1640) and fetal bovine serum (FBS) were obtained from Hyclone (Logan, UT, USA). Lipofectamine2000, TRIzol and SuperScriptII reverse transcriptase were purchased from Invitrogen (Carlsbad, CA, USA). All other chemicals were obtained from Sigma (St. Louis, MO, USA). The following antibodies were obtained from Santa Cruz: anti-CELF1 (1:1000 dilution), anti-GAPDH (glyceraldehyde-3-phosphate dehydrogenase, 1:3000 dilution) and anti-mouse HRP (1:5000 dilution).

\section{Cell culture}

Human lung cancer cells (A549 and H1299) and human embryonic kidney (HEK) $293 \mathrm{~T}$ cell lines were obtained from the cell bank of Shanghai Institute of Cell Biology. A549 and 293 T cells were maintained in DMEM supplemented with $10 \%$ heat-inactivated FBS and penicillin/ streptomycin at $37^{\circ} \mathrm{C}$ in a humidified atmosphere of $5 \%$ $\mathrm{CO}_{2}$. $\mathrm{H} 1299$ cells were maintained in RPMI 1640 medium supplemented with $10 \%$ heat-inactivated FBS and penicillin/streptomycin at $37^{\circ} \mathrm{C}$ in a humidified atmosphere of $5 \% \mathrm{CO}_{2}$.

\section{Construction of CELF1 shRNA-containing lentivirus and infection}

The sequences of CELF1 siRNA and non-silencing control siRNA were 5' -CTAGCCGGGATTGAAGAATGCC GGATATTCAAGAGATATCCGGCATTCTTCAATCT TTTTAAT-3' and 5'-CTAGCCCGGTTCTCCGAAC GTGTCACGTATCTCGAGATACGTGACACGTTCGG AGAATTTTTTTAAT-3', respectively. The nucleotide sequences were inserted into the plasmid through the pFH-L vector (Shanghai Hollybio, China) and the generated lentiviral-based shRNA-expressing vectors were confirmed by DNA sequencing. Lentiviruses were generated by transfection of $293 \mathrm{~T}$ cells at $80 \%$ confluence with generated plasmids. The cells were starved for $2 \mathrm{~h}$ before transfection, and pFH-L-shCELF1 or -shCTRL and the packaging vector carriers pVSVG-I and PCMVAR8.92 were transfected into cells using Lipofectamine 2000. The supernatant was collected $48 \mathrm{~h}$ after transfection and lentiviral particles were harvested by ultracentrifugation $(4000 \mathrm{~g})$ at $4^{\circ} \mathrm{C}$ for $10 \mathrm{~min}$. The collected virus particles were filtered through a $45 \mu \mathrm{M}$ filter and the filtrate was centrifuged $\left(4000 \mathrm{~g}\right.$ at $\left.4^{\circ} \mathrm{C}\right)$ for $15 \mathrm{~min}$ to collect the viral concentrate.

A549 and H1299 cancer cells were then infected with CELF1 shRNA- or control shRNA-expressing lentiviruses at a MOI of 30 for A549 cells or MOI of 15 for H1299 cells. The cells were seeded $\left(5 \times 10^{4}\right.$ cells per well) in six-well plates, and after $24 \mathrm{~h}$ of incubation, the culture medium was replaced with Opti-MEM medium containing the appropriate amount of the virus. The cells were then incubated with the virus for another $48 \mathrm{~h}$. Successful transfection was confirmed by observation through a fluorescence microscope (Leica, Germany) for expression of green fluorescence protein.

\section{Real-time PCR analysis}

RNA was obtained using the Total RNA Isolation Reagent $\left(A B g e n e^{\mathrm{m}}\right)$ according to the manufacturer's instructions (Abgene, Surrey, UK). Total RNA was converted to cDNA using DuraScript ${ }^{\mathrm{Tm}}$, a commercial reverse transcription kit from Sigma Aldrich. Real-time quantitative PCR analysis for the RNA extracted from lung cancer tissues and cultured lung cancer cells was performed using the SYBR Green Master Mix Kit (Applied Biosystems, Foster City, CA). In brief, each PCR reaction mixture contained $10 \mu \mathrm{l}$ of $2 \times$ SYBR Green Master Mix, $0.4 \mu \mathrm{l}$ of sense and antisense primers $(2.5 \mu \mathrm{M})$ and $10 \mathrm{ng}$ of cDNA. Reactions were run for 40 cycles, including denaturation at $95^{\circ} \mathrm{C}$ for $10 \mathrm{~min}$ and annealing at $60^{\circ} \mathrm{C}$ for $1 \mathrm{~min}$ in a total volume of $20 \mu \mathrm{l}$ using an ABI 7500 Real Time PCR platform. The primer sequences for PCR amplification of the CELF1 gene were 5'-ACCTGTTC ATCTACCACCTG-3' and 5'-GGCTTGCTGTCATTC TTCG-3'. Primer sequences for the internal control GAPDH were 5'-GACCCCTTCATTGACCTCAAC-3' and 5 '-CTTCTCCATGGTGGTGAAGA-3'. Relative gene expression levels were calculated using $2-\Delta \Delta C \mathrm{~T}$ analysis.

\section{Western blot analysis}

A549 and H1299 cells were infected with the lentivirus containing CELF1 shRNA and control shRNA for five days. The cells were then washed with cold PBS and lysed with radio-immune precipitation assay (RIPA) buffer (50 mM Tris, pH 7.5, $150 \mathrm{mM} \mathrm{NaCl}, 1 \% \mathrm{NP}-40,0.5 \%$ sodium deoxycholate, $0.1 \%$ SDS) containing phenylmethylsulfonyl fluoride (PMSF) $(1 \mathrm{mM})$ and protease inhibitors $(2 \mu \mathrm{g} / \mathrm{ml}$; Protease Inhibitor Cocktail Set III, Calbiochem) on ice for $30 \mathrm{~min}$. The supernatant was 
collected after centrifuging the cell lysate $(12,000 \times g$ for $15 \mathrm{~min}$ ) and the protein content was measured by the Lowry method. The protein concentration of each sample was adjusted to $2 \mu \mathrm{g} / \mu \mathrm{l}$ and a $20 \mu \mathrm{l}$ volume was mixed with $2 \times$ SDS sample buffer $(100 \mathrm{mM}$ Tris- $\mathrm{HCl}$, $\mathrm{pH}$ 6.8, $10 \mathrm{mM}$ EDTA, 4\% SDS, $10 \%$ glycine) and separated by electrophoresis on a $10 \%$ SDS-PAGE gel at $50 \mathrm{~V}$ for $3 \mathrm{~h}$. The gel was transferred to a PVDF membrane at $300 \mathrm{~mA}$ for $1.5 \mathrm{~h}$, and proteins were detected after primary antibody treatment overnight at $4^{\circ} \mathrm{C}$ and secondary antibody treatment for $2 \mathrm{~h}$ at room temperature using an Amersham ECL kit (GE Healthcare, UK) and exposure to X-ray film. The bands obtained were quantified with an Image Quant densitometric scanner (Molecular Dynamics, Amersham Biosciences).

\section{MTT analysis}

For the cell viability analysis, A549 and H1299 cells were first seeded $\left(2 \times 10^{3}\right.$ cells/well $)$ into a 96 -well plate and infected with CELF1 silencing or non-silencing siRNAcontaining lentivirus for $72 \mathrm{~h}$. Following infection, $20 \mu \mathrm{l}$ of MTT solution $(5 \mathrm{mg} / \mathrm{ml})$ was added to each well and cells were incubated at $37^{\circ} \mathrm{C}$ for $4 \mathrm{~h}$. The medium and MTT from the wells was removed and $200 \mu \mathrm{l}$ of DMSO was added to each well. The optical density was measured using a microplate reader at $490 \mathrm{~nm}$. Experiments were performed in triplicate.

\section{Colony formation assay}

Lung cancer cells seeded in six-well plates $\left(2 \times 10^{2}\right.$ cells/ well) were infected with CELF1 silencing and nonsilencing siRNA-containing lentivirus for $72 \mathrm{~h}$. The cells were continuously incubated, and medium was replaced with new medium every three days until 8 days of culture. The cells were then washed with PBS and fixed with $4 \%$ paraformaldehyde. The fixed cells were stained with freshly prepared diluted Giemsa stain for $20 \mathrm{~min}$. The cells were washed with double distilled water and colonies were counted using a fluorescence microscope.

\section{Consent}

Written informed consent was obtained from the patients before operation.

\section{Competing interests}

The authors declare that they have no competing interests.

\section{Authors' contributions}

LNW and YJX contributed equally to the study design, experimental work, data analysis and preparation of the manuscript. JFC, LIZ and XMM participated in the design of the study and performed the statistical analysis. JFC conceived of the study, and participated in its design and coordination and helped to draft the manuscript. All authors read and approved the final manuscript.

\section{Acknowledgements}

The authors wish to thank Yinan Liu for clinical data collection support; Xinyuan Lao for checking grammar error. This study was supported by Beijing Science New Star Plan (Z11111005450000).

\section{Author details}

${ }^{1}$ Key laboratory of Carcinogenesis and Translational Research (Ministry of Education), Central Laboratory, Peking University Cancer Hospital \& Institute, Beijing 100142, China. ${ }^{2}$ The College of Life Science and Bio-engineering, Beijing University of Technology, Beijing 100022, People's Republic of China. ${ }^{3}$ Key laboratory of Carcinogenesis and Translational Research (Ministry of Education), Department of Thoracic Surgery II, Peking University Cancer Hospital \& Institute, Beijing 100142, China.

Received: 17 June 2013 Accepted: 14 November 2013 Published: 15 November 2013

\section{References}

1. Parkin DM, Pisani P, Ferlay J: Global cancer statistics. CA: Cancer J Clin 1999, 49(1):33-64. 31.

2. Caldon CE, Lee CS, Sutherland RL, Musgrove EA: Wilms' tumor protein 1: an early target of progestin regulation in T-47D breast cancer cells that modulates proliferation and differentiation. Oncogene 2008, 27(1):126-138.

3. Yang M, Yuan F, Li P, Chen Z, Chen A, Li S, Hu C: Interferon regulatory factor 4 binding protein is a novel p53 target gene and suppresses cisplatin-induced apoptosis of breast cancer cells. Mol Cancer 2012, 11:54.

4. Klos KS, Wyszomierski SL, Sun M, Tan M, Zhou X, Li P, Yang W, Yin G, Hittelman WN, Yu D: ErbB2 increases vascular endothelial growth factor protein synthesis via activation of mammalian target of rapamycin/ p70S6K leading to increased angiogenesis and spontaneous metastasis of human breast cancer cells. Cancer Res 2006, 66(4):2028-2037.

5. Veale D, Ashcroft T, Marsh C, Gibson GJ, Harris AL: Epidermal growth factor receptors in non-small cell lung cancer. British J Cancer 1987, 55(5):513-516.

6. Timchenko NA, Welm AL, Lu X, Timchenko LT: CUG repeat binding protein (CUGBP1) interacts with the $5^{\prime}$ region of C/EBPbeta mRNA and regulates translation of C/EBPbeta isoforms. Nucleic Acids Res 1999, 27(22):4517-4525.

7. Chang ET, Donahue JM, Xiao L, Cui Y, Rao JN, Turner DJ, Twaddell WS, Wang JY, Battafarano RJ: The RNA-binding protein CUG-BP1 increases survivin expression in oesophageal cancer cells through enhanced mRNA stability. Biochem J 2012, 446(1):113-123.

8. Rattenbacher B, Beisang D, Wiesner DL, Jeschke JC, Von Hohenberg M, St Louis-Vlasova IA, Bohjanen PR: Analysis of CUGBP1 targets identifies GU-repeat sequences that mediate rapid mRNA decay. Mol Cell Biol 2010, 30(16):3970-3980.

9. Zheng Y, Miskimins WK: CUG-binding protein represses translation of p27Kip1 mRNA through its internal ribosomal entry site. RNA Biol 2011, 8(3):365-371.

10. Ward AJ, Rimer M, Killian JM, Dowling JJ, Cooper TA: CUGBP1 overexpression in mouse skeletal muscle reproduces features of myotonic dystrophy type 1. Hum Mol Gen 2010, 19(18):3614-3622

11. Kang S, Koh ES, Vinod SK, Jalaludin B: Cost analysis of lung cancer management in South Western Sydney. J Med Imaging Radiat Oncol 2012, 56(2):235-241.

12. Benjamin D, Moroni C: mRNA stability and cancer: an emerging link? Expert Opinion Biol Ther 2007, 7(10):1515-1529.

13. Cui YH, Xiao L, Rao JN, Zou T, Liu L, Chen Y, Turner DJ, Gorospe M, Wang JY: miR-503 represses CUG-binding protein 1 translation by recruiting CUGBP1 mRNA to processing bodies. Mol Biol Cell 2012, 23(1):151-162

14. Vlasova-St Louis I, Bohjanen PR: Coordinate regulation of mRNA decay networks by GU-rich elements and CELF1. Curr Opin Gen Dev 2011, 21(4):444-451.

15. Jones $K$, Timchenko L, Timchenko NA: The role of CUGBP1 in agedependent changes of liver functions. Ageing Res Rev 2012, 11(4):442-449.

16. Devi GR: siRNA-based approaches in cancer therapy. Cancer Gene Ther 2006, 13(9):819-829. 
17. Jiao W, Zhao J, Wang M, Wang Y, Luo Y, Zhao Y, Tang D, Shen Y; CUG-binding protein 1 (CUGBP1) expression and prognosis of non-small cell lung cancer. Clin Transl Oncol 2013, 15(10):789-795.

18. Talwar S, Balasubramanian S, Sundaramurthy S, House R, Wilusz CJ, Kuppuswamy D, D'Silva N, Gillespie MB, Hill EG, Palanisamy V: Overexpression of RNA-binding protein CELF1 prevents apoptosis and destabilizes pro-apoptotic mRNAs in oral cancer cells. RNA Biol 2013, 10(2):277-286.

doi:10.1186/1475-2867-13-115

Cite this article as: Wu et al:: Si-RNA mediated knockdown of CELF1

gene suppressed the proliferation of human lung cancer cells. Cancer

Cell International 2013 13:115.

\section{Submit your next manuscript to BioMed Central and take full advantage of:}

- Convenient online submission

- Thorough peer review

- No space constraints or color figure charges

- Immediate publication on acceptance

- Inclusion in PubMed, CAS, Scopus and Google Scholar

- Research which is freely available for redistribution 